Musées, Patrimoine et Culture scientifiques et techniques

$133 \mid 2011$

janvier - février 2011

\title{
À propos de Conservateurs de musées et politiques culturelles. L'impulsion territoriale de Frédéric
} Poulard

Jean-Bernard Roy

\section{OpenEdition}

Journals

Édition électronique

URL : http://journals.openedition.org/ocim/668

DOI : $10.4000 /$ ocim.668

ISSN : 2108-646X

Éditeur

OCIM

Édition imprimée

Date de publication : 1 janvier 2011

Pagination : 36-37

ISSN : 0994-1908

\section{Référence électronique}

Jean-Bernard Roy, «À propos de Conservateurs de musées et politiques culturelles. L'impulsion territoriale de Frédéric Poulard ", La Lettre de I'OCIM [En ligne], 133 | 2011, mis en ligne le 01 janvier 2013, consulté le 23 avril 2019. URL : http://journals.openedition.org/ocim/668 ; DOI : 10.4000/ ocim. 668

Ce document a été généré automatiquement le 23 avril 2019

Tous droits réservés 


\title{
À propos de Conservateurs de musées et politiques culturelles. L'impulsion territoriale de Frédéric Poulard
}

\author{
Jean-Bernard Roy
}

1 On pourrait imaginer que l'histoire récente des institutions et des politiques culturelles, telle que l'ont étudié Philippe Poirrier, Jean-Pierre Rioux, Jean-François Sirinelli, Guy Saez, Pascal Ory, et bien d'autres chercheurs est un sujet épuisé. Il n'en est rien et le récent ouvrage de Frédéric Poulard (Conservateurs de musées et politiques culturelles. L'impulsion territoriale. Paris : La Documentation Française, collection Musées-Mondes, 2010,192 p.) nous en apporte la preuve en ce qui concerne les musées.

2 Reprise d'une thèse de doctorat en sociologie, très remarquée, l'ouvrage explore avec profit le champ de l'histoire des musées et nous en livre une synthèse passionnante. L'ouvrage bouscule un certain nombre d'idées reçues. Non, l'essor des musées ne commence pas dans les années 1980, avec l'arrivée de la gauche au pouvoir, le doublement du budget de la culture et le ministère Lang. Le renouveau des musées, en France, est un phénomène continu qui s'amorce dans la période de l'entre-deux-guerres et se poursuit pendant les Trente Glorieuses. En aucun cas il ne s'agit d'une période de stagnation, une «modernisation discrète » annonce la « fièvre des musées » qui débute dès les années 1970.

3 L'auteur s'intéresse aux 1208 musées labellisés « Musées de France » depuis la loi-musées de 2002, sans privilégier les plus prestigieux d'entre eux (ceux qui ont fait l'objet des Grands Travaux présidentiels et parisiens). Son approche est double, comme sociologue $\mathrm{du}$ travail pour les conservateurs, et comme historien, pour les politiques culturelles.

4 Les deux premiers chapitres sont consacrés à cette saga des musées, à l'ère de la modernité (et de la postmodernité ?). Le troisième chapitre, à l'état présent, qui découle directement de la grande embellie des années 1980, époque marquée par une complexité plus grande dans les mécanismes de décision, une montée en force de la bureaucratie 
culturelle et une surenchère des attentes à l'égard de l'institution qui vient peut-être de connaître son âge d'or.

$5 \quad$ Les musées doivent désormais affronter de nouveaux défis avec des modes de gestion plus libéraux et une administration de plus en plus tatillonne. Les plus grands musées sont maintenant dirigés par des administrateurs recrutés en dehors du corps des conservateurs. Le remplacement est parfois brutal, comme celui du conservateur $d u$ château de Fontainebleau relaté par Frédéric Poulard. À la suite d'un échec relatif du modèle de conservateur-manager, le profil du conservateur recherché pour ses compétences scientifiques est revalorisé. L'auteur étudie les conservateurs «en situation ", non seulement au moyen d'entretiens, mais aussi par des enquêtes approfondies, en suivant les activités des professionnels au jour le jour, et dans le long terme. Un échantillon significatif reflète la grande diversité des situations. Il n'oublie pas le conservateur qui exerce dans une ville de 10000 habitants et ne dispose que d'un agent pour le seconder.

6 La réflexion des conservateurs a largement contribué à l'émergence de nouvelles politiques culturelles. Du « livre bleu » de 1969 aux réflexions des membres de la MNES (muséologie nouvelle et expérimentation sociale) il s'est constitué un ensemble de propositions sur la reconnaissance des nouveaux musées - les écomusées - la formation des conservateurs, sans oublier l'intégration de ces derniers dans la fonction publique territoriale (la filière culturelle).

7 Comme le montre Frédéric Poulard, il s'agit le plus souvent d'une véritable anticipation des politiques qui sont mises en place, pour la formation, avec l'INP (institut national du patrimoine) et un statut professionnel pour les conservateurs. La possibilité, encore timide, d'associer de nouveaux métiers au fonctionnement des musées avec les attachés de conservation, pour la médiation par exemple. Exigée pour les musées "labellisés " musées de France par la loi de 2002 sur les musées, elle ne s'apparente pas à une " délégation du sale boulot» comme semblent le penser certains, et selon la citation empruntée au sociologue américain Everett C. Hughes, rapportée par l'auteur !

En sociologue des musées, avisé, Frédéric Poulard nous livre le meilleur portrait qui puisse exister de cette profession de conservateur qui fait beaucoup fantasmer, y compris les intéressés eux-mêmes! On n'en connaît souvent que les aspects les plus conventionnels: l'expertise ou les "mondanités». L'image renouvelée qu'en donne l'auteur ne reprend pas la métaphore trompeuse des intéressés eux-mêmes, celle du " chef d'orchestre ». Il insiste avec force sur une aptitude à la relation humaine qu'il juge primordiale, une capacité indispensable à constituer un réseau relationnel pour l'aider dans toutes ses tâches professionnelles. Faute des moyens (financiers et autres) le conservateur en région se trouve obligé de trouver des compensations. On aurait envie d'ajouter: attention aux risques d'ingérence. Faut-il aller jusqu'au bénévolat, "à l'américaine ", et comment l'organiser ? Le musée est un service public, ou du moins il devrait l'être: ces principes ont été rappelés par les théoriciens des musées de société comme Hugues de Varine, mais les objectifs des populations locales ne sont pas toujours en phase avec les « projets scientifiques et culturels » des musées.

Dans cette brillante histoire des musées contemporains, Frédéric Poulard analyse de manière très perspicace le rôle des conservateurs, acteurs de terrain qui ont réussi à susciter collectivement et à titre individuel, les politiques culturelles de leurs collectivités, et celles de l'État. 


\section{AUTEUR}

JEAN-BERNARD ROY

Conservateur en chef honoraire du Patrimoine 